\title{
Leptospiraceae, a New Family to Include Leptospira Noguchi 1917 and Leptonema gen. nov.
}

\author{
KARI HOVIND-HOUGEN \\ Departments of Biophysics and Treponematoses, Statens Seruminstitut, DK-2300 Copenhagen S, Denmark
}

\begin{abstract}
The morphology of the cells of an organism formerly referred to as a member of Leptospira sp. serovar illini has been studied by electron microscopy. Cells of these strains differ morphologically from the cells of leptospires in the following: (i) cells of the former have cytoplasmic tubules which leptospires do not possess, and (ii) the structure of the basal complex on the flagella of the former is similar to that of gram-positive bacteria, whereas the corresponding structure on the flagella of leptospires is similar to that of gram-negative bacteria. Pillot (J. Pillot, thesis, University of Paris, Paris, France, 1965) proposed in 1965 that leptospires should constitute a family, Leptospiraceae. However, Pillot proposed this name in a thesis, which is not considered to be effective publication. Hence, Leptospiraceae is here proposed as the name of a new family. In consequence of the new morphological evidence presented here together with the data from other publications on the deoxyribonucleic acid base composition and serological and cultural properties of cells of strains of Leptospira sp. serovar illini, it is proposed that this family should consist of two genera: Leptospira Noguchi 1917 and Leptonema gen. nov. The type species of Leptonema is Leptonema illini, and the type strain of this species is strain 3055 (= NCTC 11301).
\end{abstract}

Strain 3055 , an organism originally identified as a leptospira, was isolated by Hanson in 1965 from the urine of a clinically healthy bull (see reference in 10). As examined by dark-field microscopy, the organism had a morphology similar to that of leptospires (10).

Tripathy and Hanson $(11,12)$ and Hanson et al. (5) published the results of various studies on the pathogenicity, antigenicity, and pathological characteristics of strain 3055 . These results are compared with those from similar studies on cells of strain A 177, a later isolate of a similar organism (5; R. D. Andrews, Ph.D. thesis, University of Illinois, Urbana, 1966). The conclusion of these studies was that strains 3055 and A 177 were closely related and that they differed in certain characteristics from other leptospires. Although Tripathy and Hanson referred to these organisms as Leptospira illini $(11,12)$, they used this name only incidentally and did not propose it as a species name; hence $L$. illini was not validly published. Both strains were found to differ phenotypically and in deoxyribonucleic acid (DNA) base content from Leptospira interrogans and in DNA base content from the freeliving nonpathogenic leptospires $(L$. biflexa $)$. It was suggested by Hanson et al. (5), however, that these strains belonged to a new serovar (serotype) of the genus Leptospira, viz., Leptospira sp. serovar illini (5).

We included serovar illini in our studies (6) on the morphology of cells of different Leptospira serovars. In the present paper the ultra- structure of these cells is described. The observed similarities and differences in the morphology of cells of serovar illini compared with those of other Leptospira serovars are presented, and the consequence of these observations on the taxonomic position of strains 3055 and A 177 is discussed.

\section{MATERIALS AND METHODS}

Bacterial strains. The following strains were studied: Leptospira serovar illini strain 3055 (5) and strain A 177 (Andrews, thesis). Both strains were obtained from H. C. Ellinghausen, National Animal Disease Center, Ames, Iowa.

Maintenance and cultivation. The strains were cultured at $29^{\circ} \mathrm{C}$ in Korthof medium (8) supplemented with ca. $9 \%$ inactivated rabbit serum, rabbit hemoglobulin, and an aqueous extract of baker's yeast (2). Five-day-old cultures $(26 \mathrm{ml})$ were centrifuged for 30 $\mathrm{min}$ in a water-cooled centrifuge at $15,000 \times \mathrm{g}$. The resulting pellet was resuspended with a Pasteur pipette in $4 \mathrm{ml}$ of Korthof medium (8).

Electron microscopy. One volume of the suspension of cells in Korthof basal medium was added to 1 volume of SMC $(0.03 \%$ sucrose in redistilled water with $0.01 \mathrm{M} \mathrm{MgCl}_{2}$ and $0.01 \mathrm{M} \mathrm{CaCl}_{2}$ ) and centrifuged at $10,000 \times g$ for $20 \mathrm{~min}$. The resulting pellet was resuspended in SMC to a suitable density.

Negative staining. Specimen grids were prepared with cells from these suspensions. The cells on some grids were further treated with drops of a solution of Myxobacter AL-1 protease (AL-1 enzyme) containing $100 \mu \mathrm{g}$ of the enzyme per $\mathrm{ml}$ and $5 \times 10^{-4} \mathrm{M}$ ethylenediaminetetraacetate in $2.5 \times 10^{-3} \mathrm{M}$ tris(hydroxymethyl)aminomethane buffer ( $\mathrm{pH} \mathrm{9.0)}$. Flagella were 
liberated from the organisms by treating suspended cells with AL-1 enzyme as described in a previous paper (7). All preparations were negatively stained by the multiple drop technique (7), and $1 \%$ ammonium molybdate $(\mathrm{pH} 7)$ was used for staining.

Sectioned material. The procedure for fixation and embedding was as given previously (1), except for preliminary fixation, where $1 \mathrm{ml}$ of $3 \%$ glutaraldehyde in redistilled water was added to $10 \mathrm{ml}$ of a cell suspension in Korthof medium (8). Only cells of strain 3055 were studied in sectioned material.

Electron microscopy. Electron microscopy was carried out on Philips EM 200 and EM 300 electron microscopes at primary magnifications of $\times 1,600$, $\times 9,000, \times 16,000$, and $\times 17,500$. Negatives were obtained on Kodak Fine Grain Release Positive Film, Type 5302 , and were photographically enlarged as desired. In the present investigation, about 300 micrographs were made and studied.

\section{RESULTS}

Negatively stained material. Cells of strains 3055 and A 177 were found to be morphologically identical, and they are therefore described together as follows. The negatively stained cells showed a regular wavy outline and were 13 to $21 \mu \mathrm{m}$ long and $0.1 \mu \mathrm{m}$ wide (Fig. 1). Generally, the cells had hook-shaped ends (Fig. 1); however, cells with straight ends were occasionally seen. The wavelength of the coils was $0.6 \mu \mathrm{m}$, and the amplitude was about $0.1 \mu \mathrm{m}$. A single flagellum was inserted at either end of the cell, and in well-preserved cells each flagellum was entwined with the helical cell body for about four to six turns of the helix (Fig. 2). Cytoplasmic tubules with a diameter of about $7 \mathrm{~nm}$ were observed in cells accidentally damaged during preparation for electron microscopy as well as in cells which were treated with AL-1 enzyme (Fig. 3 and 4). The cytoplasmic tubules appeared in bundles with three to four tubules in each (Fig. 3 and 4). One end of the bundle was close to the insertion point of the flagellum (Fig. 4), and the length of the tubules was approximately the same as that of the flagellum. The middle part of each organism was thus devoid of flagella as well as of cytoplasmic tubules.

Flagella were loosened from their attachment to the cells when cell suspensions were treated with AL-1 enzyme (Fig. 5 and 6). Often these free flagella did not have the helical shape they possessed in the intact organisms but were found coiled up in spirals (like the balance spring of a clock) (Fig. 5). Each flagellum consisted of a core covered by a sheath; frequently the distal ends of flagella were unsheathed (Fig. 7). The diameter of the core was $10 \mathrm{~nm}$, and that of the sheathed filament was about $16 \mathrm{~nm}$. The insertion part of a flagellum resembled the corresponding part on a flagellum isolated from a gram-positive bacterium (4), i.e., a basal knob consisting of two thin disks in close apposition to each other and a neck about $10 \mathrm{~nm}$ long connecting the basal knob to the hook at the proximal end of the flagellum (Fig. 5 and 6).

Sectioned material. The general morphology of cells of strain 3055 , as seen in sectioned material, was similar to that of cells of leptospires in similarly treated material $(1,6,9)$. Flagella were observed in several transversely sectioned cells. They were situated in the interspace between the cell envelope and the peptidoglycan layer (Fig. 8, inserts). However, evidence of cytoplasmic tubules was also found in some transversely sectioned, as well as longitudinally sectioned, cells (Fig. 8). In the transversely sectioned cells the cytoplasmic tubules were situated in the cytoplasm close to the inner leaflet of the cytoplasmic membrane and just underneath the flagellum (Fig. 8, insert B).

\section{DISCUSSION}

The gross morphology of cells of strains 3055 and A 177 is identical to that of cells of the various serovars of the genus Leptospira previously studied $(6,9)$. However, cytoplasmic tubules were observed in the illini cells when these were accidentally damaged during preparation for electron microscopy or examined after treatment with AL-1 enzyme. Cytoplasmic tubules have never been observed in the cells of the other Leptospira serovars examined, viz. pomona, patoc, icterohaemorrhagiae, and canicola (6), although they have been observed in cells of strains of the genera Treponema and Spirochaeta.

Fibrils have been reported to protrude from cells of serovar icterohaemorrhagiae after treatment with deoxycholate and trypsin (13) and from cells of serovar biflex $a$ after treatment with alkali or hyaluronidase (14). In these reports it was emphasized that these fibrils were only observed when cells were treated as specified, and it was inferred that the fibrils originated from the outer envelope of the cells. However, negative staining was not used in any of these studies, and it is thus difficult to judge whether or not the fibrils were the same as the cytoplasmic tubules observed in the present study.

Ritchie (9) published electron micrographs which demonstrated rapidosomes in negatively stained cells of serovar icterohaemorrhagiae. However, he regarded the rapidosomes as being organelles different from the cytoplasmic tubules (body fibrils) present in cells of strains of the genera Treponema and Spirochaeta, and thus they must also be different from the cytoplasmic tubules observed in the illini cells. 


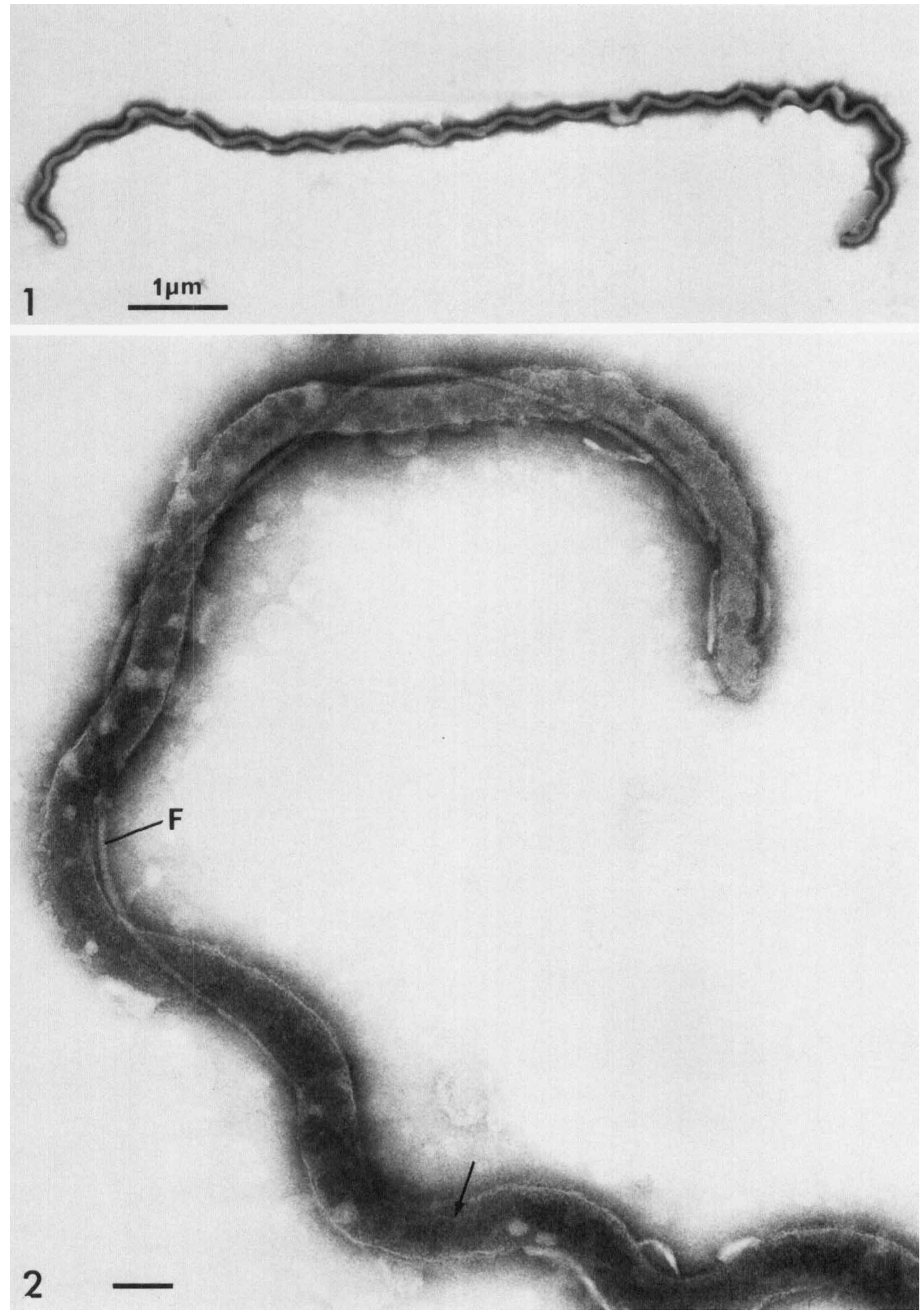

Fig. 1. Cell of L. illini A 177 negatively stained with 1\% ammonium molybdate. A regularly waved cell showing hook-shaped ends. $\times 15,000$.

FIg. 2. Cell of L. illini 3055 stained as in Fig. 1. A higher magnification of the hook-shaped end of a cell. The flagellum $(F)$ is entwined with the cell body for approximately four wave-lengths. The end of the flagellum is marked with an arrow. $\times 90,000 ;$ bar, $100 \mathrm{~nm}$. 


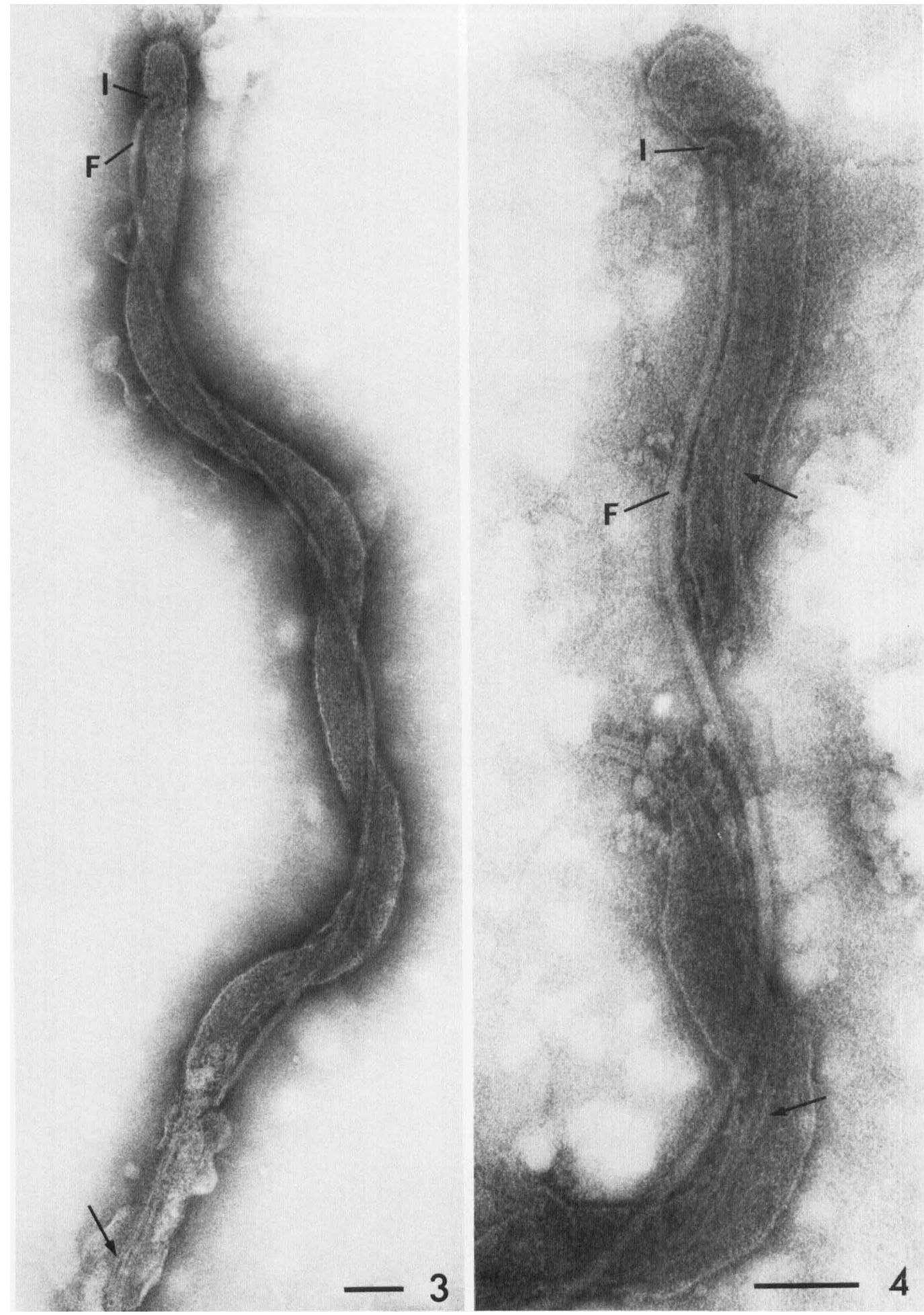

FIG. 3 and 4. L. illini 3055 cell stained as in Fig. 1. These figures illustrate that the cytoplasmic tubules appear in bundles of three to four tubules (arrows). Note that the upper part of the bundle in Fig. 4 is in close apposition to the insertion point (I) of the flagellum $(F)$. The microtubules are broken as a result of the specimen preparation. The cell in Fig. 3 was accidentally damaged during preparation for electron microscopy, and the cell in Fig. 4 was treated in suspension with AL-1 enzyme. Fig. 3, $\times 90,000$, and Fig. 4, $\times 160,000 ;$ bars, $100 \mathrm{~nm}$. 

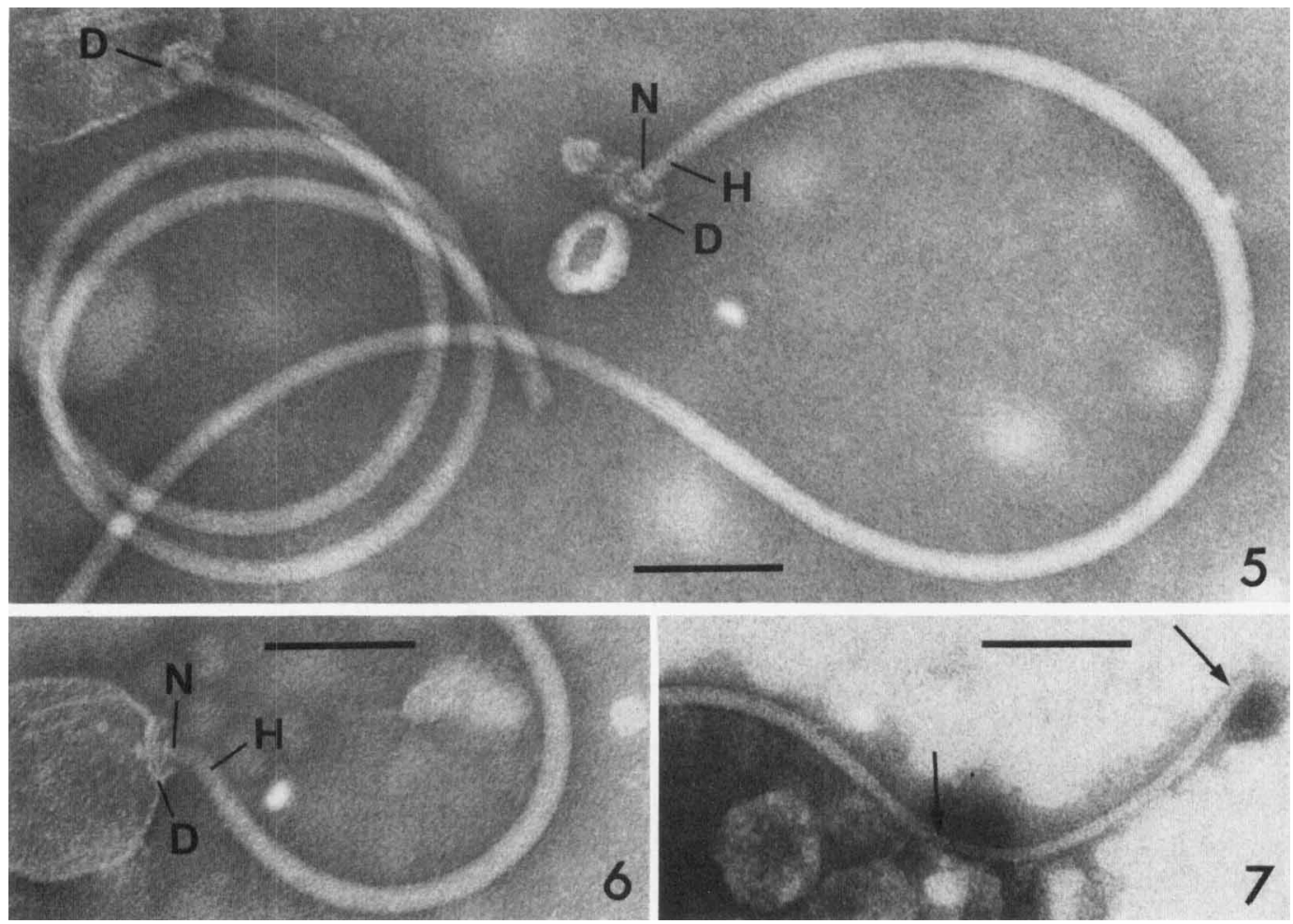

FIG. 5-7. These figures show individual flagella obtained from L. illini 3055 cell suspensions treated with AL-1 enzyme and stained as in Fig. 1. Many free flagella were coiled up in spirals after this treatment (Fig. 5). The substructure of the insertion part or basal knob of the flagellum is seen in Fig. 5 and 6 . Note that the basal knob consists of a single pair of disks (D) and that these are connected by a neck (N) to a hook $(H)$ at the end of the flagellum. In Fig. 7 is shown how the sheath of the shaft of the flagellum often is shorter than the core, so that the distal end of the flagellum is left unsheathed (arrows). Fig. 5, 6, and 7, $\times 160,000 ;$ bars, 100 $\mathrm{nm}$.

Another difference between cells of the two illini strains and those of the other leptospires was in the insertion organelles of the flagella. In cells of strains 3055 and A 177 these organelles were seen to be of the same type as those found on flagella detached from gram-positive bacteria, whereas the corresponding structures on flagella isolated from other leptospires have been similar to those found on flagella from gram-negative bacteria.

Strains 3055 and A 177 have been shown to be antigenically distinct from all known pathogenic or saprophytic serovars of the genus Leptospira, but they react to the same high titer with their own and with each other's antiserum $(5,11)$. The guanine plus cytosine content in the DNA of strain 3055 was found to be $53 \mathrm{~mol} \%$ (3) and that of A 177 was $51.2 \mathrm{~mol} \%$ (5). These values are considerably different from those of other Leptospira serovars, which generally have guanine plus cytosine values in the range of 35.2 to $41.2 \mathrm{~mol} \%$ (3). Furthermore, strains 3055 and
A 177 are the only leptospires known to be capable of growing in Trypticase soy broth without any additional serum (5). Hanson et al. (5) referred to strain 3055 as a member of Leptospira sp. serovar illini on the basis of serological, cultural, and DNA base content differences between cells of strain 3055 and representatives of known leptospiral serovars $(11,12)$ and, presumably, because the International Committee on Systematic Bacteriology Subcommittee on the Taxonomy of Leptospira had decided to recognize only one species of Leptospira, L. interrogans.

Leptospires are the only known aerobic members of the order Spirochaetales, and they are also morphologically distinguishable from the other members of this order. By electron microscopy, the flagella of leptospires are seen to entwine with the cell body for only $1 / 4$ to $1 / 3$ of the cell length, thus leaving the middle part of the cell devoid of flagella. Furthermore, in the leptospires examined so far, the insertion struc- 


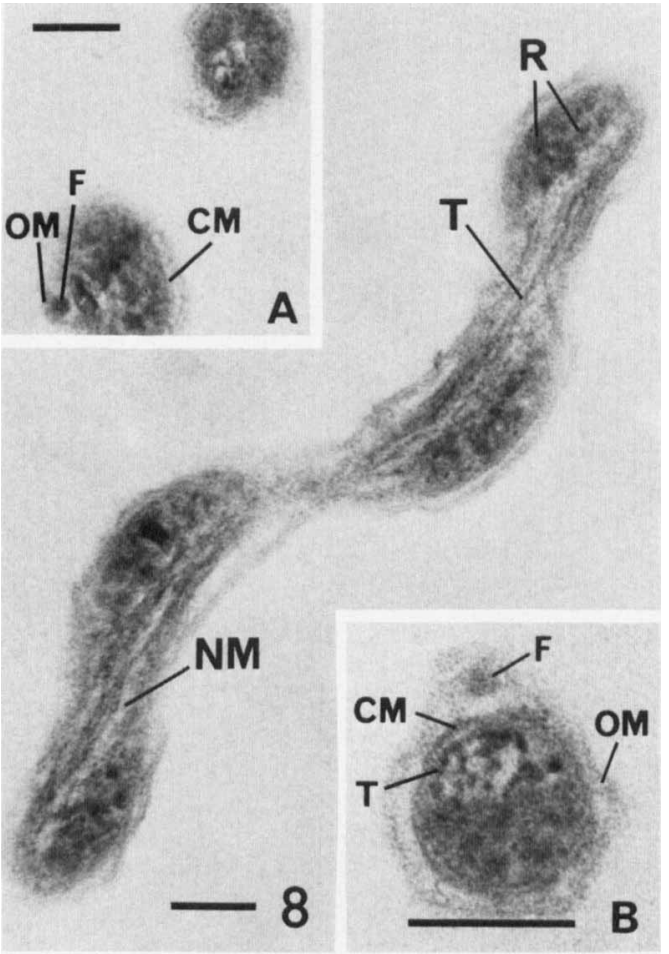

Fig. 8. Sectioned cells of L. illini. Inserts $A$ and $B$ show transversely sectioned cells. In these, the flagella $(F)$ are seen situated between the outer membrane (OM) and the cytoplasmic membrane (CM) of the cells. Cytoplasmic tubules (T) are present in the cytoplasm just underneath the flagellum and close to the inner leaflet of the cytoplasmic membrane (insert $B)$. The main figure shows part of a longitudinally sectioned cell. Some cytoplasmic tubules $(T)$ can here be distinguished in the cell interior together with ribosomes ( $R$ ) and nuclear material (NM). Fig. 8 and insert $A, \times 90,000$; insert $B, \times 175,000$; bars, $100 \mathrm{~nm}$.

tures (basal complex) of the flagella have all been shown to be identical with those of the flagella of gram-negative bacteria $(4,6)$. In contrast, the corresponding organelles on the flagella isolated from cells of the two illini strains resemble those found on flagella of gram-positive bacteria.

On the basis of the evidence presented here, I support the proposal by Pillot (J. Pillot, thesis, University of Paris, Paris, France, 1965) that the genus Leptospira be excluded from the family Spirochaetaceae and that it be placed in a family of its own. Pillot proposed the name Lepto. spiraceae for this family. However, this proposal was made in his thesis, which is not considered to be effective publication. Hence this name was not validly published, and it is thus without standing in nomenclature. Consequently Leptospiraceae fam. nov. is here proposed as the name of the family based on the genus Leptospira. The results of previous studies $(5,10-12)$ and those of the presently described study indicate that the family Leptospiraceae should consist of at least two genera: (i) Leptospira Noguchi 1917, the nomenclatural type of the family, and (ii) Leptonema, a new genus to include the illini strains.

Leptospiraceae fam. nov. (M.L. fem.n. Leptospira type genus of the family; -aceae ending to denote a family; M.L. fem.pl.n. Leptospiraceae the Leptospira family). Description taken in part from "Definition of genus Leptospira," International Committee on Systematic Bacteriology Subcommittee on the Taxonomy of Leptospires, Munich, 1978, to be published.

Unicellular, flexible, motile, helicoidal, gramnegative organisms which measure 0.1 by 6 to $20 \mu \mathrm{m}$; the wavelength (pitch) is about $0.5 \mu \mathrm{m}$. One or both ends of a cell are usually hooked or bent. The organisms have two flagella, one inserted subterminally at each end of the cell. Aerobic and microaerophilic cells occur. The organisms are chemo-organotrophic; they can usually be cultivated in media containing serum, serum albumin, or long-chain fatty acids (14 carbons or more) as major sources of carbon and energy. Ammonia in the form of inorganic salts, rather than amino acids, usually satisfies the nitrogen requirements. Purines, but not pyrimidines, are utilized. The family includes strains that are parasitic or free living. Some strains may be pathogenic for humans or various other animal species.

The type genus is Leptospira Noguchi 1917. The morphological, cultural, and physiological characteristics of this genus are in general those of the family Leptospiraceae. The organisms have no cytoplasmic tubules. The flagella are inserted into the soma by a basal body with two pairs of disks, similar to the basal body on the flagella of gram-negative bacteria. The guanine plus cytosine content of the DNA (in the species examined) ranges from 35.2 to $41.2 \mathrm{mo} 1 \%$. Serum or long-chain fatty acids are required for growth. Growth occurs in Trypticase broth with additional serum. Habitat is as for the family.

The type species is Leptospira interrogans (Stinson) Wenyon 1926.

Leptonema gen. nov. (Lep.to.ne'ma. Gr.adj. leptos thin, narow, fine; Gr.n. nema a thread; M.L. neut.n. Leptonema a thin thread). Morphological characteristics are in general those of the family Leptospiraceae, but flagella are inserted in the soma by a basal body with a single pair of disks, similar to the basal body on flagella of gram-positive bacteria, and two bundles of 
cytoplasmic tubules lie close to the innermost layer of the cytoplasmic membrane. The bundles originate from the ends of the cell. Serum or long-chain fatty acids are required for growth. Grows on Trypticase soy broth without additional serum. The guanine plus cytosine content of the DNA is 51.2 to $53 \mathrm{~mol} \%$.

The type species is Leptonema illini sp. nov. The morphological, cultural, and physiological characteristics of this species are those of the genus Leptonema. Nonpathogenic for hamsters, mice, gerbils, guinea pigs and cattle.

The type strain of L. illini is strain 3055 . Its characteristics are those as given above for the species and genus. A culture of this strain has been deposited in the National Collection of Type Cultures, London, England under the number 11301.

\section{LITERATURE CITED}

1. Birch-Andersen, A., K. Hovind-Hougen, and C. Borg-Petersen. 1973. Electron microscopy of Leptospira. I. Leptospira strain pomona. Acta Pathol. Microbiol. Scand. Sect. B 81:665-676.

2. Borg-Petersen, C., and A. Fagraeus. 1947. The influence of the antigen density and other factors on the serum titer in the agglutination-lysis-test for leptospirosis. Acta Pathol. Microbiol. Scand. 26:555-567.

3. Brendle, J. J., M. Rogul, and A. D. Alexander. 1974. Deoxyribonucleic acid hybridization among selected leptospiral serotypes. Int. J. Syst. Bacteriol. 24:205214.
4. DePamphilis, M. L., and J. Adler. 1971. Fine structure and isolation of the hook-basal body complex of flagella from Escherichia coli and Bacillus subtilis. J. Bacteriol. 105:384-395.

5. Hanson, L. E., D. N. Tripathy, L. B. Evans, and A. D. Alexander. 1974. An unusual leptospira, serotype illini (a new serotype). Int. J. Syst. Bacteriol. 24:355-357.

6. Hovind-Hougen, K. 1976. Determination by means of electron microscopy of morphological criteria of value for classification of some spirochetes, in particular treponemes. Acta Pathol. Microbiol. Scand. Sect. B, Suppl. 255 , p. $28-30$.

7. Hovind-Hougen, K., and A. Birch-Andersen. 1971. Electron microscopy of endoflagella and microtubules in Treponema Reiter. Acta Pathol. Microbiol. Scand. Sect. B 79:37-50.

8. Korthof, G. 1928. Proven met Leptospira icterohaemorrhagiae. Versl. Meded. Volksgezond. 2:1272-1285.

9. Ritchie, A. H. 1976. Morphology of leptospires, p. 19-37. In $\mathrm{R}$. C. Johnson (ed.), The biology of parasitic spirochetes. Academic Press, London.

10. Tripathy, D. N., and L. E. Hanson. 1972. Colonial and morphologic variations of Leptospira illini strain 3055 Am. J. Vet. Res. 33:1723-1727.

11. Tripathy, D. N., and L. E. Hanson. 1973. Studies of Leptospira illini, strain 3055: pathogenicity for different animals. Am. J. Vet. Res. 34:557-562.

12. Tripathy, D. N., and L. E. Hanson. 1973. Studies of Leptospira illini, strain 3055: immunological and serological determinations. Am. J. Vet. Res. 34:563-565.

13. Yanagawa, R., and S. Faine. 1966. Morphological and serological analysis of leptospira structure. Nature (London) 211:823-826.

14. Yanagihara, Y., and I. Mifuchi. 1968. Microfibers present in surface structure of Leptospira. J. Bacteriol. 95: 2403-2406. 